\title{
INSPECTION POLICIES IN AIRCRAFT SERVICE
}

\author{
K.N. Nechval*, N.A. Nechval**, E.K. Vasermanis** \\ *Computer Science Department, Institute of Transport and Telecommunication, Lomonosov Street 1, LV-1019 Riga, \\ Latvia \\ **Mathematical Statistics Department, University of Latvia, Raina Blvd 19, LV-1050 Riga, Latvia. \\ E-mail: nechval@junik.lv \\ Received 0110 2004, accepted 13122004
}

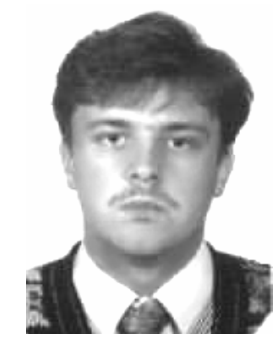

Konstantin N. NECHVAL, PhD student

Date and place of birth: 1975 in Riga, Latvia.

Education: 1998 - Aviation University of Riga, MS Degree.

Research interests: Stochastic Processes, Pattern Recognition, Operations Research, Statistical Decision Theory and Adaptive Control.

Present position: PhD student in automatic control and systems engineering at Riga Technical University.

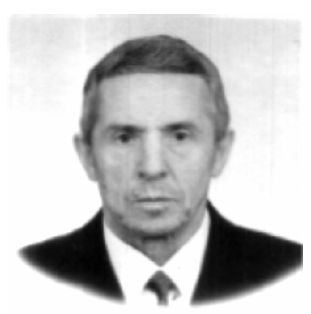

Nicholas A. NECHVAL, Prof

Education: 1969 - Riga Civil Aviation Engineers Institute, $\mathrm{PhD}$

Affiliations and functions: 1993 - DSc degree in radio engineering at Riga Aviation University; Professor of Applied Mathematics at RAU from 1993 to 1999. At present, he is Professor of Mathematics and Computer Science at the University of Latvia.

Research interests: Mathematics, Stochastic Processes, Pattern Recognition, Multidimensional Statistical Detection and Estimation, Multiresolution Stochastic Signal Analysis, Digital Radar Signal Processing, Operations Research, Statistical Decision Theory, and Adaptive Control.

Professional memberships: Member of Latvian Statistical Association, Institute of Mathematical Statistics, CHAOS asambl (Institute of Mathematics, based in Liege, Belgium), Latvian Association of Professors.

Awards: 1992 - Silver Medal of the Exhibition Committee (Moscow, Russia) in connection with research on the problem of Prevention of Collisions between Aircraft and Birds.

Patents: Several patents in Radio Engineering.

Present position: Professor of Mathematics and Computer Science at the University of Latvia

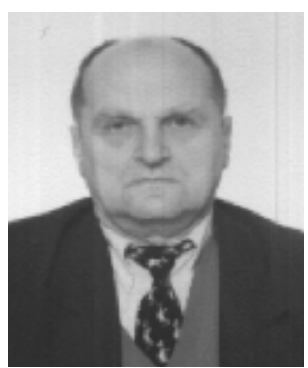

Edgars VASERMANIS, Prof

Education: 1974 - Riga Civil Aviation Engineers Institute (RCAEI), PhD degree in automatic control and systems engineering; 1989 - Tallinn University, DSc degree in economics and management.

Professional memberships: A professional member of the Latvian Statistical Association and the Institute of Mathematical Statistics. He is a member of the Latvian Association of Professors.

Research interests: Economics and management, operations research, statistical decision theory, and adaptive control.

Present position: Dean of the Faculty of Economics and Management at the University of Latvia.

Abstract. As aircraft structures begin to age (that is, as flight hours accumulate), existing subcritical cracks or new cracks can grow in some high-stress points of the structural components. The usual approach is to inspect the structures periodically. Thus, a catastrophic accident during flight can be avoided. The problem then arises of choosing a sequence of inspection times which avoids both too many inspections, which may be costly, and too few inspections, that may also be costly due to a crack in an aircraft structure component not being detected for a long period. In this paper, a simple approach is proposed, where after each inspection (if a crack is not detected), we choose the next inspection point so that a crack may occur within an interval between successive inspection times with a given probability. It allows one to find the inspection policies for detection of initial cracks in critical structural components of aircraft under the assumption that the parameter values of the underlying distributions are unknown; this constraint is often met in practice. Furthermore, obtaining inspection schedules under crack propagation is considered. To illustrate the proposed technique based on ancillary statistics, numerical examples are given.

Keywords: aircraft structures, fatigue cracks, inspection policies, detection.

\section{Introduction}

Fatigue life of structural components of aircraft is affected by the randomness of loads, structural geometry, material properties, and other factors, and this recommends the adoption of probabilistic approaches. The fatigue life of components is predominantly controlled by the growth of pre-existing defects that lead 
to small cracks. There are two methods for the evaluation of fatigue life - the (S-N) approach, which is used at the design stage, and the fracture mechanics approach. The $(\mathrm{S}-\mathrm{N})$ approach predicts fatigue damage as a function of the number of cycles at various stress levels. It is a relatively simple method to apply, but it depends on the geometry under consideration. Fracture mechanics provides an approach of determining the fatigue life of cracked components. Once a crack is detected, the integrity of the structure can be evaluated and crack growth can be predicted by fracture mechanics.

The total fatigue life of a structural component is the sum of the time to crack initiation and the time of crack propagation until critical crack size. The period of crack initiation is short relative to the crack propagation period. However, for a very small initial defect and low load levels, there may be a significant crack initiation period. In order to avoid a catastrophic accident during flight, the usual approach is to inspect the structures at certain intervals. This paper deals with the case when the fatigue crack can be detected only by actual inspection. Scheduling of inspection times appears in a variety of reliability applications, quality control, medicine, nuclear energy, defence, etc. Examples include maintaining continuous production processes (e.g., replacing worn-out tools in automated manufacturing systems), monitoring quality, stand-by systems, alarm systems, planning checkups for ageing aircraft, and so on. In many cases, there are estimable costs associated with the elapsed time between system failure and its detection. For example, if the system is a production system, the costs are associated with the amount of defective products (e.g., products manufactured outside tolerance limits), and the state of the system, good or failed, can only be determined by an inspection (e.g., by checking the quality of machine output). Thus, in such cases, it is important to inspect the unit from time to time in order to determine its condition. However, since these inspections are often costly, inspection times must be chosen so that undetected failure (or late detection) costs and inspection costs are balanced optimally. A commonly used inspection policy with constant intervals between inspections is not optimal relative to a certain cost model; optimum inspection policies have decreasing inspection intervals for aging systems. However, it may be quite difficult to find such an optimum policy. Different authors have produced many interesting and significant results for variations of inspection models The different models developed depend on the assumptions made regarding the time horizon, the amount of information available, the nature of cost functions, the objective of the models, the system's constraints, etc. The different models, for the most part, however, are very similar to a basic model presented by Barlow, Barlow and Proschan [1, 2]. This basic model is a pure inspection model, i.e. no preventive maintenance is assumed, and the system is not replaced on failure.

In this paper, we investigate this inspectionscheduling problem and derive optimal schedules over the time span extended only until detection of failure under the main assumption that there is no knowledge concerning the parameters of the distribution function $\mathrm{F}(\mathrm{x})$ of the lifetime of the system. This constraint is often met in practice. A simple approach is proposed for situations in which it is difficult to quantify the costs associated with inspections and undetected failure or when these costs vary in time. This allows one to find the inspection policies for detection of initial cracks in critical structural components of aircraft under the assumptions that the parameter values of the underlying distributions are unknown. Furthermore, obtaining inspection schedules under crack propagation is considered.

\section{Models for detection of system failures}

Interest in optimal inspection schedules for the maintenance of stochastically failing or deteriorating systems originated with the work of many authors. A fundamental initial contribution is that of Barlow, Barlow and Proschan $[1,2]$. They developed a simple two-state inspection model capturing very effectively the fundamental trade-off involved in the choice of an optimum inspection schedule; frequent checks increase the cost of inspections, but decrease the costs of late detection of failure.

Barlow formulated a pure inspection model for a system [1]. They considered the simplest possible case of an inspection policy, which is characterized by the following assumptions:

1) The system's conditions are classified into states 0 and 1 . State 0 denotes a functioning state, and state 1 denotes a failed state.

2) The system's condition is known by inspection only. In particular, system failure is known only through inspection.

3) Inspections are perfect in the sense that failure will be identified at inspection.

4) Inspection does not degrade or rejuvenate the system.

5) The system cannot fail or age during inspection.

6) An inspection takes negligible time.

7) Each inspection entails a fixed $\operatorname{cost} c_{i}$, and the fixed cost rate of leaving an undetected failure is $\mathrm{k}_{\mathrm{f}}$ (this may be the scrap cost, reworking cost, or lost production cost).

8) Inspection ceases upon detection of failure; specifically, no replacement or repair takes place.

9) The system starts at time 0 in the functioning state; the time to failure is a random variable $\mathrm{X}$, with known distribution $\mathrm{F}_{\theta}(\mathrm{x})$, survivor $\overline{\mathrm{F}}_{\theta}(\mathrm{x})=1-\mathrm{F}_{\theta}(\mathrm{x})$, density $\mathrm{f}_{\theta}(\mathrm{x})$, and parameter $\theta$ (in general, vector). In this context, a policy consists of a schedule of

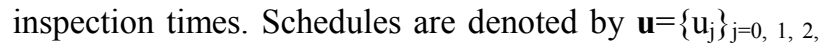

$\equiv\left(\mathrm{u}_{0}, \mathrm{u}_{1}, \mathrm{u}_{2}, \ldots\right)$, where $\mathrm{u}_{\mathrm{j}}$ is the time of the $\mathrm{jth}$ inspection, $u_{j}>u_{j-1}$, and $u_{0} \equiv 0$. For each schedule $\mathbf{u}$, only a subset of the inspections will actually be carried out. Then, the expected total cost is obtained as follows:

$$
\mathrm{E}\{\mathrm{C}(\mathbf{u})\}=\sum_{\mathrm{j}=1}^{\infty} \int_{\mathrm{u}_{\mathrm{j}}}^{\mathrm{u}_{\mathrm{j}+1}}\left[\mathrm{c}_{1}(\mathrm{j}+1)+\mathrm{c}_{2}\left(\mathrm{u}_{\mathrm{j}+1}-\mathrm{x}\right)\right] \mathrm{dF}_{\theta}(\mathrm{x}) .
$$


Barlow showed that if the hazard function $\mathrm{h}_{\theta}(\mathrm{x})=\mathrm{f}_{\theta}(\mathrm{x}) / \overline{\mathrm{F}}_{\theta}(\mathrm{x})$ is increasing, then the optimal inspection intervals are non-increasing. The optimum inspection schedule $\mathbf{u}^{*}$ is the one that minimizes $\mathrm{E}\{\mathrm{C}(\mathbf{u})\}$. A necessary condition for the existence of a minimumcost inspection schedule is that $\partial \mathrm{E}\{\mathrm{C}(\mathbf{u})\} / \partial \mathrm{u}_{\mathrm{j}}=0$ for all $\mathrm{j}$. Therefore, differentiating Eq. (1) with respect to $u_{j}$ and setting the associated derivative to zero, we obtain the recurrence relation among the $u_{j}$ 's given by

$$
u_{j+1}-u_{j}=\frac{F_{\theta}\left(u_{j}\right)-F_{\theta}\left(u_{j-1}\right)}{f_{\theta}\left(u_{j}\right)}-\frac{c_{1}}{c_{2}} \text { for } j=1,2, \ldots .
$$

Barlow et al. proposed an algorithm to seek the optimal inspection schedule, which minimises Eq. (1) by using the recurrence relation (2) [1]. However, using this algorithm makes it difficult to obtain the optimum inspection schedule numerically because the computations are repeated until the schedule is determined to the required degree by changing the first inspection time $t_{1}$, and the assumption on $h_{\theta}(x)$ is restrictive. A second, more fundamental problem is the difficulty, in many situations, of assigning quantitative values to any costs due to undetected failure or to inspections. Thirdly, even in situations where quantitative costs can be assigned, these costs will often not be fixed. The cost of an inspection may vary with time and with various other factors, such as the availability of technicians, and the cost due to undetected failures may also depend on a variety of factors, which may be changing with time. To overcome these problems, some improved algorithms have been proposed.

Munford and Shahani suggested an algorithm based on a single parameter to determine a near optimum inspection schedule [7]. They also showed that their algorithm has the property of generating decreasing, increasing, or constant intervals between successive inspection times if the system has an increasing, a decreasing, or a constant hazard function $\mathrm{h}_{\theta}(\mathrm{x})$ respectively. Additionally, Munford and Shahani applied the algorithm for the Weibull lifetime distribution case, while Tadikamalla did the same for the gamma case [8, 15]. Both cases show that the results obtained from the algorithm compare well with those proposed by Barlow et al., but the latter is computationally more difficult.

Nakagawa and Yasui suggested an approximate calculation of the optimum inspection schedule [9]. They computed successive inspection times backwards, assuming that an appropriate inspection time is given after a large number of inspections. They gave a numerical example to show that the approximation can be fairly good for a Weibull distribution, claimed that the algorithm could be applied to other distribution cases, and concluded that the computation is much easier than those of Barlow et al. and Munford et al.

Keller [6] utilized optimal control theory for an approximate method of selecting the inspection schedule that, for a system subject to failure, will minimize cost until the detection of the first failure. Each inspection has $\operatorname{cost} c_{1}$, and $\operatorname{cost} c_{2}$ is incurred when detection of the failure by an inspection occurs at time $\mathrm{x}$ after failure. This problem is placed in the control theory framework by assuming that the tests are so frequent that they can be described by a smooth density $\mathrm{j}(\mathrm{x})$ which denotes the number of checks per unit time. In other words, at time $x$, the tests are scheduled $1 / \mathrm{j}(\mathrm{x})$ units of time apart. Keller then derived an integral equation for $\mathrm{j}(\mathrm{x})$ and used this solution to minimize the expected cost up to detection of the first failure.

Kaio and Osaki suggested an algorithm by developing that of Keller, i.e. based on a continuous inspection density to determine a near optimum inspection schedule $[5,6]$. The continuous inspection density $\mathrm{j}(\mathrm{x})$ denotes the approximate number of inspections per unit time at time $\mathrm{x}$, under the assumption that inspections are frequently made. Then the expected total cost up to detection of system failure is approximately

$$
E\{C[j(x), u]\}=c_{1} \int_{0}^{\infty} j(x) \bar{F}_{\theta}(x) d x+c_{2} \int_{0}^{\infty} \frac{1}{2 j(x)} d_{\theta}(x) .
$$

The density $j(x)$ which minimises $E\{C[j(x), u]\}$ in Eq. (3) is

$$
j(x)=\sqrt{\frac{c_{2} h_{\theta}(x)}{2 c_{1}}} .
$$

The inspection times $u_{j}(j=1,2, \ldots)$ satisfy

$$
j=\int_{0}^{u_{j}} j(x) d x \quad \text { for } j=1,2, \ldots
$$

Substituting for $\mathrm{j}(\mathrm{x})$ in Eq. (4) into Eq. (5) yields the near optimum inspection schedule.

Kaio and Osaki compared Barlow et al.'s algorithm (to seek the optimum inspection schedule) with Munford and Shahani's, Nakagawa and Yasui's, and Kaio and Osaki's algorithms (to seek near optimal inspection schedules) [4]. They applied these algorithms to the Weibull and the gamma distributions respectively. They concluded that there are no significant differences between the optimal schedule and the three near optimal inspection schedules in both cases, but recommended Kaio and Osaki's algorithm for the following three reasons: (1) it is the simplest algorithm to compute, (2) there is no restriction on a system lifetime distribution, and (3) it can incorporate more complicated inspection policies; see Kaio and Osaki [3].

In this paper, we derive optimum inspection policies using an approach similar to that of Munford and Shahani under the assumption that the parameter values of the underlying distributions are unknown; this is often found to be realistic in practice [7].

\section{Inspection policy for detection of initial cracks}

Suppose an inspection is carried out at time $t$, and this shows that an initial crack (which may be detected) has not yet occurred. We now have to schedule the next 
inspection. Let $\mathrm{X}$ be the random time to crack initiation. Then we schedule the next inspection at time $u>t$, where $u$ satisfies

$$
\operatorname{Pr}\{\mathrm{X}>\mathrm{u} ; \mathrm{X}>\mathrm{t}\}=1-\alpha .
$$

Equation (6) says that the next inspection is scheduled so that, with probability $1-\alpha$, the aircraft structure component is still working and free of initial crack prior to inspection.

\subsection{Complete Information about $F_{\theta}(x)$}

Let $\mathrm{F}_{\theta}(\mathrm{x})$ be the cumulative distribution function of the time to crack initiation, where $\theta$ is a known parameter (in general, vector). Then the inspection times $\left(\mathrm{u}_{1}, \mathrm{u}_{2} \ldots\right)$ can be calculated recursively as follows. It follows from (6) that

$$
\frac{\bar{F}_{\theta}\left(u_{j+1}\right)}{\bar{F}_{\theta}\left(u_{j}\right)}=1-\alpha, j \geq 0,
$$

where $\overline{\mathrm{F}}_{\theta}(\mathrm{u})=1-\mathrm{F}_{\theta}(\mathrm{u})$. It can be shown that (7) is equivalent to the equation

$$
\begin{aligned}
& 1-\frac{\bar{F}_{\theta}\left(u_{j+1}\right)}{\bar{F}_{\theta}\left(u_{j}\right)}=\frac{\bar{F}_{\theta}\left(u_{j}\right)-\bar{F}_{\theta}\left(u_{j+1}\right)}{\bar{F}_{\theta}\left(u_{j}\right)}=\frac{1-F_{\theta}\left(u_{j}\right)-\left[1-F_{\theta}\left(u_{j+1}\right)\right]}{1-F_{\theta}\left(u_{j}\right)} \\
& =\frac{F_{\theta}\left(u_{j+1}\right)-F_{\theta}\left(u_{j}\right)}{1-F_{\theta}\left(u_{j}\right)}=\alpha, j \geq 0
\end{aligned}
$$

that is, in other words, the probability that the microcrack occurs in the time interval $\left(\mathrm{u}_{\mathrm{j}}, \mathrm{u}_{\mathrm{j}+1}\right)$ without crack at time $u_{j}$ is always assumed $\alpha$.

It follows from (7) that

$$
\overline{\mathrm{F}}_{\theta}\left(\mathrm{u}_{\mathrm{j}+1}\right)=(1-\alpha) \overline{\mathrm{F}}_{\theta}\left(\mathrm{u}_{\mathrm{j}}\right), \quad \mathrm{j} \geq 0 .
$$

With $\mathrm{u}_{0}=0, \mathrm{u}_{1}, \mathrm{u}_{2}, \ldots$ can be calculated recursively from (9). So that:

$$
\bar{F}_{\theta}\left(u_{j}\right)=(1-\alpha)^{j}, \quad j=1,2,3, \ldots,
$$

the time $u_{j}(j=1,2,3, \ldots)$ is given by

$$
\mathrm{u}_{\mathrm{j}}=\overline{\mathrm{F}}_{\theta}^{-1}\left[(1-\alpha)^{\mathrm{j}}\right], \quad \mathrm{j}=1,2,3, \ldots .
$$

Let $\mathrm{N}$ be the random number of inspections until the initial crack occurs. Then

$$
\operatorname{Pr}\{\mathrm{N} \leq \mathrm{j}\}=\operatorname{Pr}\left\{\mathrm{X} \leq \mathrm{u}_{\mathrm{j}}\right\}=\mathrm{F}_{\theta}\left(\mathrm{u}_{\mathrm{j}}\right)
$$

and

$$
\begin{aligned}
& E\{N\}=\sum_{j=0}^{\infty} j \operatorname{Pr}\{N=j\}=\sum_{j=1}^{\infty} j[\operatorname{Pr}\{N>j-1\}-\operatorname{Pr}\{N>j\}] \\
& =\sum_{j=0}^{\infty} \operatorname{P}\{N>j\}=\sum_{j=0}^{\infty} \bar{F}_{\theta}\left(u_{j}\right)=\alpha^{-1} .
\end{aligned}
$$

For example, if $\alpha=0.05$ then, from (13), on average 20 inspections will be necessary.

\subsection{Incomplete Information about $F_{\theta}(x)$}

Let us assume that the parameter $\theta$ is unknown, but there is a sample of observations $\mathrm{X}^{\mathrm{n}}=\left(\mathrm{X}_{1}, \mathrm{X}_{2}, \ldots \mathrm{X}_{\mathrm{n}}\right)$ from $\mathrm{F}_{\theta}(\mathrm{x})$. Let $\mathrm{W}=\left(\mathrm{X}, \mathrm{X}^{\mathrm{n}}\right)$ be an ancillary statistic the distribution of which does not depend on $\theta$ [10-12]. Then we schedule the next inspection at time $u>t$ on the basis of relation

$$
\operatorname{Pr}\left\{\mathrm{W}>\mathrm{w}_{\mathrm{u}} ; \mathrm{W}>\mathrm{w}_{\mathrm{t}}\right\}=\frac{\operatorname{Pr}\left\{\mathrm{W}>\mathrm{w}_{\mathrm{u}}\right\}}{\operatorname{Pr}\left\{\mathrm{W}>\mathrm{w}_{\mathrm{t}}\right\}}=1-\alpha,
$$

where $\mathrm{w}_{\mathrm{t}}=\mathrm{w}\left(\mathrm{t}, \mathrm{x}^{\mathrm{n}}\right), \mathrm{w}_{\mathrm{u}}=\mathrm{w}\left(\mathrm{u}, \mathrm{x}^{\mathrm{n}}\right)$.

Example 1. Let $\mathrm{X}_{(1)}<\mathrm{X}_{(2)}<\ldots<\mathrm{X}_{(\mathrm{r})}$ be the first $\mathrm{r}$ ordered observations of time to crack initiation for identical structural components of aircraft from a sample of size $n$ from a two-parameter Weibull distribution with probability density function

$$
f(x ; \sigma, \delta)=\left\{\begin{array}{lr}
\frac{\delta}{\sigma}\left(\frac{x}{\sigma}\right)^{\delta-1} \exp \left[-(x / \sigma)^{\delta}\right], & x \geq 0, \\
0, & \text { otherwise }
\end{array}\right.
$$

(as the results of fatigue tests conducted on the components), where $\theta=(\sigma, \delta)$, the parameters $\sigma$ and $\delta$ $(\sigma>0, \delta>0)$ are unknown, i.e. we deal with Type II censoring. Let us assume that in a fleet of $\mathrm{k}$ aircraft there is $\mathrm{km}$ of the same individual structural components, operating independently. Suppose an inspection is carried out at time $\mathrm{u}_{\mathrm{j}}$, and this shows that an initial crack (which may be detected) has not yet occurred. We now have to schedule the next inspection. Let $\mathrm{Y}_{(1)}$ be the minimum time to crack initiation in the above components. In other words, let $Y_{(1)}$ be the smallest observation from an independent second sample of $\mathrm{km}$ observations also from the distribution (15). Then the inspection times can be calculated recursively as

$$
\mathrm{u}_{\mathrm{j}+1}=\hat{\sigma} \exp \left(\mathrm{w}_{\mathrm{j}+1} / \widehat{\delta}\right), \mathrm{j} \geq 1,
$$

where $u_{1}$ is a time of the first inspection, $w_{j+1}$ is determined from

$$
\operatorname{Pr}\left\{\mathrm{W}>\mathrm{w}_{\mathrm{j}+1} ; \mathrm{W}>\mathrm{w}_{\mathrm{j}},{ }^{\circ} \mathrm{W}^{\mathrm{r}}={ }^{\bullet} \mathrm{w}^{\mathrm{r}}\right\}=\frac{\operatorname{Pr}\left\{\mathrm{W}>\mathrm{w}_{\mathrm{j}+1} \dot{\bullet}^{\cdot} \mathrm{w}^{\mathrm{r}}\right\}}{\operatorname{Pr}\left\{\mathrm{W}>\mathrm{w}_{\mathrm{j}} ;{ }^{\bullet} \mathrm{w}^{\mathrm{r}}\right\}}
$$

$$
\begin{aligned}
& =\frac{\operatorname{Pr}\left\{\hat{\delta} \ln \left(\frac{\mathrm{Y}_{(1)}}{\hat{\sigma}}\right)>\mathrm{w}_{\mathrm{j}+1} \dot{*}^{\cdot} \mathrm{w}^{\mathrm{r}}\right\}}{\operatorname{Pr}\left\{\hat{\delta} \ln \left(\frac{\mathrm{Y}_{(1)}}{\hat{\sigma}}\right)>\mathrm{w}_{\mathrm{j}} ; \mathrm{w}^{\mathrm{r}}\right\}} \\
& =\left(\begin{array}{l}
\int_{0}^{\infty} \mathrm{s}^{\mathrm{r}-2} \mathrm{e}^{\mathrm{s} \hat{\delta} \sum_{\mathrm{i}=1}^{\mathrm{r}} \ln \left(\mathrm{x}_{(\mathrm{i})} / \hat{\sigma}\right)} \\
\times\left(\mathrm{km} \mathrm{e}^{\mathrm{sw} \mathrm{j}+1}+\sum_{\mathrm{i}=1}^{\mathrm{r}} \mathrm{e}^{\mathrm{s} \hat{\delta} \ln \left(\mathrm{x}_{(\mathrm{i})} / \sigma\right)}+(\mathrm{n}-\mathrm{r}) \mathrm{e}^{\mathrm{s} \hat{\delta} \ln \left(\mathrm{x}_{(\mathrm{r})} / \hat{\sigma}\right)}\right)^{-\mathrm{r}} \mathrm{ds}
\end{array}\right)
\end{aligned}
$$




$$
\begin{aligned}
& \times\left(\int_{0}^{\infty} \mathrm{s}^{\mathrm{r}-2} \mathrm{e}^{\mathrm{s} \hat{\mathrm{\delta}} \sum_{\mathrm{i}=1}^{\mathrm{r}} \ln \left(\mathrm{x}_{(\mathrm{i})} / \hat{\sigma}\right)} \times\left(\mathrm{km} \mathrm{e}^{\mathrm{sw} \mathrm{j}_{\mathrm{j}}}+\sum_{\mathrm{i}=1}^{\mathrm{r}} \mathrm{e}^{\mathrm{s} \hat{\delta} \ln \left(\mathrm{x}_{(\mathrm{i})} / \hat{\sigma}\right)}+(\mathrm{n}-\mathrm{r}) \mathrm{e}^{\mathrm{s} \hat{\delta} \ln \left(\mathrm{x}_{(\mathrm{r})} / \sigma\right)}\right)^{-\mathrm{r}} \mathrm{ds}\right)^{-1} \\
& =1-\alpha, \quad \mathrm{j} \geq 1, \\
& \text { where }
\end{aligned}
$$

$$
\operatorname{Pr}\left\{\mathrm{W}>\mathrm{w} ; \mathrm{w}^{\mathrm{r}}\right\}=\operatorname{Pr}\left\{\widehat{\delta} \ln \left(\frac{\mathrm{Y}_{(1)}}{\hat{\sigma}}\right)>\mathrm{w} ; \mathrm{w}^{\mathrm{r}}\right\}
$$

$$
=\left(\begin{array}{l}
\int_{0}^{\infty} \mathrm{s}^{\mathrm{r}-2} \mathrm{e}^{\mathrm{s} \hat{\delta} \sum_{\mathrm{i}=1}^{\mathrm{r}} \ln \left(\mathrm{x}_{(\mathrm{i})} / \hat{\sigma}\right)} \\
\times\left(\mathrm{km} \mathrm{e}^{\mathrm{sw}}+\sum_{\mathrm{i}=1}^{\mathrm{r}} \mathrm{e}^{\mathrm{s} \widehat{\delta} \ln \left(\mathrm{x}_{(\mathrm{i})} / \hat{\sigma}\right)}+(\mathrm{n}-\mathrm{r}) \mathrm{e}^{\mathrm{s} \hat{\delta} \ln \left(\mathrm{x}_{(\mathrm{r})} / \hat{\sigma}\right)}\right)^{-\mathrm{r}} \mathrm{ds}
\end{array}\right)
$$$$
\times\left(\int_{0}^{\infty} \mathrm{s}^{\mathrm{r}-2} \mathrm{e}^{\mathrm{s} \hat{\delta} \sum_{\mathrm{i}=1}^{\mathrm{r}} \ln \left(\mathrm{x}_{(\mathrm{i})} / \sigma\right)}\left(\sum_{\mathrm{i}=1}^{\mathrm{r}} \mathrm{e}^{\mathrm{s} \hat{\delta} \ln \left(\mathrm{x}_{(\mathrm{i})} / \sigma\right)}+(\mathrm{n}-\mathrm{r}) \mathrm{e}^{\mathrm{s} \hat{\delta} \ln \left(\mathrm{x}_{(\mathrm{r})} / \sigma\right)}\right)^{-\mathrm{r}} \mathrm{ds}\right)^{-1},
$$

$$
{ }^{\bullet} \mathrm{W}^{\mathrm{r}}=\left({ }^{\bullet} \mathrm{W}_{1}, \ldots,{ }^{\bullet} \mathrm{W}_{\mathrm{r}}\right), \quad{ }^{\cdot} \mathrm{W}_{\mathrm{i}}=\widehat{\delta} \ln \left(\frac{\mathrm{X}_{(\mathrm{i})}}{\hat{\sigma}}\right), \quad \mathrm{i}=1(1) \mathrm{r},
$$

$\widehat{\sigma}$ and $\bar{\delta}$ are the MLE's of $\sigma$ and $\delta$, respectively, and can be found from solution of

$$
\begin{aligned}
& \hat{\sigma}=\left(\frac{\sum_{i=1}^{r} x_{(i)}^{\widehat{\delta}}+(n-r) x_{(r)}^{\widehat{\delta}}}{r}\right]^{1 / \widehat{\delta}}, \\
& \widehat{\delta}=\left[\begin{array}{l}
\left(\sum_{i=1}^{r} x_{(i)}^{\widehat{\delta}} \ln x_{(i)}+(n-r) x_{(r)}^{\widehat{\delta}} \ln x_{(r)}\right) \\
\left.\times\left(\sum_{i=1}^{r} x_{(i)}^{\widehat{\delta}}+(n-r) x_{(r)}^{\widehat{\delta}}\right)^{-1}-\frac{1}{r} \sum_{i=1}^{r} \ln x_{(i)}\right]^{-1} .
\end{array}\right.
\end{aligned}
$$

For instance, consider the data of fatigue tests on a particular type of structural components of aircraft IL-86. The data are for a complete sample of size $r=n=5$, with observations results being expressed here in number of $10^{4}$ flight-hours.

Table 1. The data of fatigue tests on a particular type of structural components of IL-86aircraft

\begin{tabular}{|c|c|}
\hline Observations & $\begin{array}{l}\text { Time to fatigue crack initiation } \\
\text { (in number of } 10^{4} \text { flight-hours) }\end{array}$ \\
\hline $\mathrm{x}_{(1)}$ & 5 \\
\hline $\mathrm{x}_{(2)}$ & 6.25 \\
\hline $\mathrm{x}_{(3)}$ & 7.5 \\
\hline $\mathrm{x}_{(4)}$ & 7.9 \\
\hline $\mathrm{x}_{(5)}$ & 8.1 \\
\hline
\end{tabular}

On the basis of these data, the desire is to derive an optimum inspection policy for a group of $\mathrm{m}=5$ identical components (for a fleet of $\mathrm{k}=1 \mathrm{IL}-86$ aircraft) that are to be put into service. We assume that all $\mathrm{m}$ components are inspected at the same times.

Goodness-of-fit testing. Many methods, such as Chi-square or the Kolmogorov-Smirnov, exist for determining the goodness of fit of a probability distribution to a set of data. The Anderson-Darling test was chosen for this study as it is more sensitive to the tail behavior and has been recommended for statistical analysis of the data of fatigue damage of materials. The sensitivity to the tail behavior is particularly useful in structural engineering applications, where the tail is important in computing the structural reliability. The Anderson-Darling statistic is obtained as:

$$
\mathrm{A}_{\mathrm{n}}^{2}=\mathrm{n} \int_{-\infty}^{\infty} \frac{\left[\widetilde{\mathrm{F}}_{\mathrm{n}}(\mathrm{x})-\mathrm{F}_{0}(\mathrm{x})\right]^{2}}{\mathrm{~F}_{0}(\mathrm{x})\left[1-\mathrm{F}_{0}(\mathrm{x})\right]} \mathrm{dF}_{0}(\mathrm{x}),
$$

in which $\widetilde{F}_{\mathrm{n}}(\mathrm{x})$ is a step function that jumps at the order statistics of $\mathrm{x}$, and $\mathrm{F}_{0}(\mathrm{x})$ is the hypothesized continuous cumulative distribution function. The Anderson-Darling statistic is a measure of the square of the error between the data and the hypothesized distribution weighted so that the tails of the data are more important than the central portion. For computation purposes, the Anderson-Darling statistic can be obtained as:

$$
\mathrm{A}_{\mathrm{n}}^{2}=\sum_{\mathrm{i}=1}^{\mathrm{n}}\left(\frac{1-2 \mathrm{i}}{\mathrm{n}}\left[\ln \left(\mathrm{F}_{0}\left(\mathrm{x}_{(\mathrm{i})}\right)\right)+\ln \left(1-\mathrm{F}_{0}\left(\mathrm{x}_{(\mathrm{n}+1-\mathrm{i})}\right)\right)\right]\right)-\mathrm{n},
$$

in which $\mathrm{x}_{(\mathrm{i})}$ is the ith order statistic of the data set. For the Weibull distribution with the maximum likelihood estimates of unknown parameters, an observed significance level (OSL) is obtained as follows [14]:

$$
\mathrm{OSL}=\frac{1}{1+\exp \left(-0.10+1.24 \ln \mathrm{AD}^{\bullet}+4.48 \mathrm{AD}^{\bullet}\right)},
$$

where

$$
\mathrm{AD}^{\bullet}=\left(1+\frac{0.2}{\sqrt{\mathrm{n}}}\right) \mathrm{A}_{\mathrm{n}}^{2} \text {. }
$$

The OSL is the probability of obtaining a value of the test statistic at least as large as that obtained from the data if the hypothesis that the data are actually from the distribution being tested is true. Typically, a 5\% significance level is used, so that the null hypothesis is only rejected if the OSL is less than 0.05 .

It follows from (20) and (21) that the maximum likelihood estimates of unknown parameters $\sigma$ and $\delta$ are $\hat{\sigma}=7.42603$ and $\hat{\delta}=7.9081$, respectively. Then, for this example,

$$
\text { OSL }=0.30175>0.05 \text {. }
$$

Thus, there is not evidence to rule out the Weibull model.

Thus, using (16) with $\mathrm{u}_{1}=4.558595\left(\times 10^{4}\right.$ flighthours) (the time of the first inspection), we have obtained the following inspection time sequence (Table 2). 
Table 2. The inspection time sequence

\begin{tabular}{|c|c|c|}
\hline $\mathrm{w}_{\mathrm{j}}$ & $\begin{array}{c}\text { Time } \\
\mathrm{u}_{\mathrm{j}}\left(\times 10^{4} \text { flight- }\right. \\
\text { hours })\end{array}$ & $\begin{array}{c}\text { Interval } \\
\text { (flight-hours }) \\
\mathrm{u}_{\mathrm{j}+1}-\mathrm{u}_{\mathrm{j}}\end{array}$ \\
\hline $\mathrm{w}_{1}=-3.85897$ & $\mathrm{u}_{1}=4.558595$ & - \\
\hline $\mathrm{w}_{2}=-3.44800$ & $\mathrm{u}_{2}=4.801761$ & 2431.66 \\
\hline $\mathrm{w}_{3}=-3.15474$ & $\mathrm{u}_{3}=4.983170$ & 1814.09 \\
\hline $\mathrm{w}_{4}=-2.92590$ & $\mathrm{u}_{4}=5.129477$ & 1463.07 \\
\hline $\mathrm{w}_{5}=-2.73805$ & $\mathrm{u}_{5}=5.252782$ & 1233.05 \\
\hline $\mathrm{w}_{6}=-2.57851$ & $\mathrm{u}_{6}=5.359829$ & 1070.47 \\
\hline$\vdots$ & $\vdots$ & $\vdots$ \\
\hline
\end{tabular}

Some authors prefer to describe the time to crack initiation by the lognormal distribution, although there is not much experimental evidence to choose one or the other. However, since the initiation time is quite small compared to the propagation time, the different choice may not have a large impact.

\section{Inspection policy under crack propagation}

Two main approaches are available for the evaluation of fatigue. The one perhaps more oriented to design formulations is the $(\mathrm{S}-\mathrm{N})$ approach that predicts the fatigue damage as a function of the number of cycles at various stress levels. It is a relatively simple method to apply but it depends on the geometry under consideration. The other approach is fracture mechanics. This method can predict crack size as a function of time and the Paris and Erdogan equation may be used:

$$
\frac{\mathrm{da}(\mathrm{x})}{\mathrm{dx}}=\mathrm{Q}[\mathrm{a}(\mathrm{x})]^{\mathrm{B}},
$$

where $a(x)$ is the crack size of a fastener hole at $x$ flight-hours, and Q and B are material parameters [13]. This model has been used successfully to describe the observed propagation of a dominant crack in many experiments and the values Q \& B have been established for a wide range of materials. Integrating Eq. (27) from $\mathrm{x}=0$ to $\mathrm{x}=\tau$, one obtains the relation between the crack size, $a(\tau)$, at any service time $\tau$ and the initial crack size, $\mathrm{a}(0)$, as follows

$$
\mathrm{a}(\tau)=\frac{\mathrm{a}(0)}{\left[1-[\mathrm{a}(0)]^{\mathrm{B}-1}(\mathrm{~B}-1) \mathrm{Q} \tau\right]^{1 /(\mathrm{B}-1)}} .
$$

For the special case in which $\mathrm{B}=1$, it can easily be shown that

$$
\mathrm{a}(\tau)=\mathrm{a}(0) \exp (\mathrm{Q} \tau)
$$

Available in-service inspection data for various types of aircraft indicate that the Weibull or lognormal distribution provides a reasonable fit for B and Q in both cases. In this paper, for the sake of simplicity but without loss of generality, only the special case in which $B=1$ is considered. This suggests, by taking logarithm, the following model

$$
\ln [\mathrm{a}(\tau)]=\ln [\mathrm{a}(0)]+\mathrm{Q} \tau,
$$

where $Q$ follows a Weibull distribution, the cumulative distribution function of which is given by

$$
F_{\theta}(q)=\left\{\begin{array}{lr}
1-\exp \left[-(q / \sigma)^{\delta}\right], & q \geq 0, \\
0, & \text { otherwise }
\end{array}\right.
$$

with $\theta=(\sigma, \delta)$. Let $h^{\bullet}$ be the operational limit crack size for the degradation path, which is permitted for the initial crack to grow and reach $\mathrm{h}^{\bullet}$ at time $\mathrm{x}=\mathrm{T}^{\bullet}$. We can then write

$$
\ln \left(\mathrm{h}^{\bullet}\right)=\ln [\mathrm{a}(0)]+\mathrm{QT}^{\bullet},
$$

where

$$
\mathrm{T}^{\bullet}=\left[\ln \left(\mathrm{h}^{\bullet}\right)-\ln (\mathrm{a}(0))\right] / \mathrm{Q}
$$

represents a time permitted for the initial crack to grow and reach the operational limit crack size $h^{\bullet}$. The distribution function of $\mathrm{T}^{\bullet}$ is given by

$$
\begin{aligned}
& \mathrm{G}\left(\mathrm{t}^{\bullet}\right)=\operatorname{Pr}\left\{\mathrm{T}^{\bullet} \leq \mathrm{t}^{\bullet}\right\} \\
& =\operatorname{Pr}\left\{\frac{\ln \left(\mathrm{h}^{\bullet} / \mathrm{a}(0)\right)}{\mathrm{Q}} \leq \mathrm{t}^{\bullet}\right\}=\operatorname{Pr}\left\{\mathrm{Q} \geq \frac{\ln \left(\mathrm{h}^{\bullet} / \mathrm{a}(0)\right)}{\mathrm{t}^{\bullet}}\right\} \\
& =1-\mathrm{F}_{\theta}\left(\frac{\ln \left(\mathrm{h}^{\bullet} / \mathrm{a}(0)\right)}{\mathrm{t}^{\bullet}}\right)=\exp \left[-\left(\frac{\ln \left(\mathrm{h}^{\bullet} / \mathrm{a}(0)\right)}{\sigma \mathrm{t}^{\bullet}}\right)^{\delta}\right], \mathrm{t}^{\bullet}>0 .
\end{aligned}
$$

Thus, $\mathrm{Z} \equiv \mathrm{Q}=\left[\ln \left(\mathrm{h}^{\bullet} / \mathrm{a}(0)\right)\right] / \mathrm{T}^{\bullet}$ follows a Weibull distribution with the cumulative distribution function

$$
F_{\theta}(z)=\left\{\begin{array}{lr}
1-\exp \left[-(z / \sigma)^{\delta}\right], & z \geq 0, \\
0, & \text { otherwise, }
\end{array}\right.
$$

Let $Z^{\mathrm{n}}=\left(Z_{1}, Z_{2}, \ldots, Z_{\mathrm{n}}\right)$ be a sample of observations of size $n$ from (35) (as the results of fatigue tests conducted on the identical components), where the parameters $\sigma$ and $\delta(\sigma>0, \delta>0)$ are unknown. When there is only one structural component with crack that is still operational at the inspection time $u_{j}$, then the next inspection time is $\mathrm{u}_{\mathrm{j}+1}$, which is the solution of

$$
\mathrm{u}_{\mathrm{j}+1}=\frac{\ln \left(\mathrm{h}^{\bullet} / \mathrm{a}(0)\right)}{\hat{\sigma} \exp \left(\mathrm{w}_{\mathrm{j}+1} / \hat{\delta}\right)}, \quad \mathrm{j} \geq 1,
$$

where $\mathrm{w}_{\mathrm{j}+1}$ is determined from

$$
\begin{aligned}
& \operatorname{Pr}\left\{\mathrm{W}>\mathrm{w}_{\mathrm{j}+1} ; \mathrm{W}>\mathrm{w}_{\mathrm{j}} \cdot{ }^{\cdot} \mathrm{W}^{\mathrm{n}}={ }^{\cdot} \mathrm{w}^{\mathrm{n}}\right\} \\
& =\frac{\operatorname{Pr}\left\{\mathrm{W}>\mathrm{w}_{\mathrm{j}+1} ; \dot{ }^{\mathrm{n}}\right\}}{\operatorname{Pr}\left\{\mathrm{W}>\mathrm{w}_{\mathrm{j}} ; \mathrm{w}^{\mathrm{n}}\right\}}=\frac{\operatorname{Pr}\left\{\widehat{\delta} \ln \left(\frac{\mathrm{Z}}{\hat{\sigma}}\right)>\mathrm{w}_{\mathrm{j}+1} ; \dot{w}^{\mathrm{n}}\right\}}{\operatorname{Pr}\left\{\hat{\delta} \ln \left(\frac{\mathrm{Z}}{\hat{\sigma}}\right)>\mathrm{w}_{\mathrm{j}} ; \mathrm{w}^{\mathrm{n}}\right\}}
\end{aligned}
$$

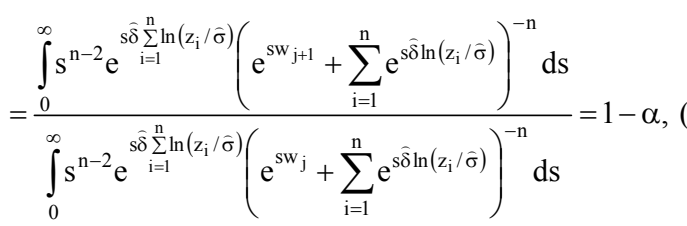




$$
\begin{aligned}
& \operatorname{Pr}\left\{\mathrm{W}>\mathrm{w} ; \dot{w}^{\mathrm{n}}\right\}=\operatorname{Pr}\left\{\widehat{\delta} \ln \left(\frac{\mathrm{Z}}{\bar{\sigma}}\right)>\mathrm{w} ; \dot{\omega}^{\mathrm{n}}{ }^{\mathrm{n}}\right\}
\end{aligned}
$$

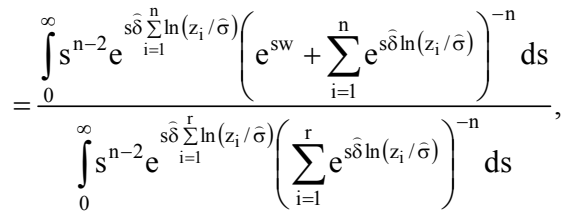

$$
\begin{aligned}
& { }^{\bullet} \mathrm{W}^{\mathrm{n}}=\left({ }^{\bullet} \mathrm{W}_{1}, \ldots,{ }^{\bullet} \mathrm{W}_{\mathrm{n}}\right),{ }^{\bullet} \mathrm{W}_{\mathrm{i}}=\widehat{\delta} \ln \left(\frac{\mathrm{Z}_{\mathrm{i}}}{\hat{\sigma}}\right), \mathrm{i}=1(1) \mathrm{n},
\end{aligned}
$$

$\widehat{\sigma}$ and $\widehat{\delta}$ are the MLE's of $\sigma$ and $\delta$ respectively and can be found from the solution of

$$
\begin{aligned}
& \hat{\sigma}=\left(\frac{1}{n} \sum_{i=1}^{n} z_{i}^{\hat{\delta}}\right)^{1 / \widehat{\delta}}, \\
& \widehat{\delta}=\left[\left(\sum_{i=1}^{n} z_{i}^{\widehat{\delta}} \ln z_{i}\right)\left(\sum_{i=1}^{n} z_{i}^{\delta}\right)^{-1}-\frac{1}{n} \sum_{i=1}^{n} \ln z_{i}\right]^{-1} .
\end{aligned}
$$

\section{Conclusions}

In this paper, we present innovative statistical models for decision-making in aircraft service. The results of computer simulations confirm the validity of the theoretical predictions of performance of the suggested models. The authors hope that this work will stimulate further investigation using the approach on specific applications to see whether results obtained with it are feasible for realistic applications.

\section{Acknowledgments}

The authors wish to acknowledge the partial support of this research by the Latvian Council of Science and the National Institute of Mathematics and Informatics of Latvia under Grant No. 02.0918 and Grant No. 01.0031.

\section{References}

1. Barlow R.E., Hunter L.C., Proschan F. Optimum Checking Procedures // Journal of the Society Industrial and Applied Mathematics. -1963. - Vol. 11. - P. 1078-1095.
2. Barlow R.E., Proschan F. Mathematical Theory of Reliability. - New York: Wiley, 1965.

3. Kaio N., Osaki S. Analytical Considerations on Inspection Policies // Stochastic Models in Reliability Theory /Edited by S. Osaki, Y. Hatoyama. - Berlin: Springer, 1984. - P. 53-71.

4. Kaio N., Osaki S. Comparison of Inspection Policies // Journal of the Operational Research Society. 1989. - Vol 40. - P. 499 - 503.

5. Kaio N., Osaki S. Some Remarks on Optimum Inspection Policies // IEEE Transactions on Reliability. - 1984. - Vol R-33. -P. 277-279.

6. Keller J.B. Optimum Checking Schedules for Systems Subject to Random Failure // Management Science. - 1974. - Vol 21. - P. 256-260.

7. Munford A.G., Shahani A.K. A Nearly Optimal Inspection Policy // Operational Research Quarterly. 1972. - Vol 23. - P. 373-379.

8. Munford A.G., Shahani A.K. An Inspection Policy for the Weibull Case // Operational Research Quarterly. - 1973 -Vol 24. - P. 453-458.

9. Nakagawa T., Yasui K. Approximate Calculation of Optimal Inspection Times // Journal of the Operation Research Society. - 1980. - Vol 31. - P. 851-853.

10. Nechval N.A. Modern Statistical Methods of Operations Research. - Riga: RCAEI, 1982.

11. Nechval N.A. Theory and Methods of Adaptive Control of Stochastic Processes. - Riga: RCAEI, 1984.

12. Nechval N.A., Nechval K.N., Vasermanis E.K. State Estimation of Stochastic Systems with Cost for Observation // IJCAS (International Journal of Computing Anticipatory Systems). - 2002. - Vol 11. - P. 350-364.

13. Paris P., Erdogan F. A Critical Analysis of Crack Propagation Laws // Journal of Basic Engineering. 1963. - Vol 85. - P. 528-534.

14. Rust S.W., Todt F.R., Harris B. et al. Statistical Methods for Calculating Material Allowables for MIL-HDBK-17 // Test Methods for Design Allowables for Fibrous Composites. - 1989. - ASTM STP 1003. - P. 136-149.

15. Tadikamalla P.R. An Inspection Policy for the Gamma Failure Distributions // Journal of the Operational Research Society. - 1979. - Vol 30. - P. $77-80$. 